\title{
Polymorphisms in pattern recognition receptors and their relationship to infectious disease susceptibility in pigs
}

\author{
Hirohide Uenishi ${ }^{*}$, Hiroki Shinkai ${ }^{1,2}$, Takeya Morozumi ${ }^{2}$, Yoshihiro Muneta ${ }^{3}$, Kosuke Jozaki ${ }^{4}$, Chihiro Kojima-Shibata ${ }^{5}$ \\ , Eisaku Suzuki ${ }^{5}$
}

From International Symposium on Animal Genomics for Animal Health (AGAH 2010)

Paris, France. 31 May - 2 June 2010

\begin{abstract}
Background: Pattern recognition receptors (PRRs), including Toll-like receptors (TLRs), are censoring receptors for molecules derived from bacteria, viruses, and fungi. The PRR system is a prerequisite for proper responses to pathogens, for example by cytokine production, resulting in pathogen eradication. Many cases of polymorphisms in PRR genes affecting the immune response and disease susceptibility are known in humans and mice.

Methods: We surveyed polymorphisms in pig genes encoding PRRs and investigated the relationship between some of the detected polymorphisms and molecular function or disease onset.

Results: Nonsynonymous polymorphisms abounded in pig TLR genes, particularly in the region corresponding to the ectodomains of TLRs expressed on the cell surface. Intracellular TLRs such as TLR3, TLR7, and TLR8, and other intracellular PRRs, such as the peptidoglycan receptor NOD2 and viral RNA receptors RIG-I and MDA5, also possessed nonsynonymous polymorphisms. Several of the polymorphisms influenced molecular functions such as ligand recognition. Polymorphisms in the PRR genes may be related to disease susceptibility in pigs: pigs with a particular allele of TLR2 showed an increased tendency to contract pneumonia.
\end{abstract}

Conclusions: We propose the possibility of pig breeding aimed at disease resistance by the selection of PRR gene alleles that affect pathogen recognition.

\section{Background}

As part of the innate immune system, both vertebrates and invertebrates possess pattern recognition receptors (PRRs), which respond to various kinds of molecules that characterize pathogens. Normally, PRR responses are quick, and their signals induce the production of proinflammatory cytokines and interferons, which are required for the appropriate exertion of other responses, including acquired immunity [1]. Vertebrates have fewer PRRs than invertebrates, but more than 30 genes encoding PRRs have been identified in each mammalian genome. In humans and mice, many studies have shown

\footnotetext{
* Correspondence: huenishi@affrc.go.jp

'National Institute of Agrobiological Sciences, Tsukuba, Ibaraki 305-8602, Japan

Full list of author information is available at the end of the article
}

that some of the polymorphisms in PRR genes influence the immune response and disease susceptibility [2]. This suggests correlations between the immune response and PRR polymorphisms in pigs [3]. It is possible that these relationships could be used for breeding aimed at disease resistance. Here, we summarize the results of our searches for polymorphisms in PRRs and the influence of these polymorphisms on ligand recognition ability. The results of our preliminary study of the relationship between TLR2 polymorphism and the onset of pneumonia imply that PRR polymorphisms also affect disease resistance in pigs.

\section{Methods}

We used Landrace, Large White, Duroc, Berkshire, Hampshire, Middle Yorkshire, Clawn miniature,
C Biomed Central

C 2011 Uenishi et al; licensee BioMed Central Ltd. This is an open access article distributed under the terms of the Creative Commons Attribution License (http://creativecommons.org/licenses/by/2.0), which permits unrestricted use, distribution, and reproduction in any medium, provided the original work is properly cited. 
Potbelly, Meishan, and Jinhua breed pigs and Japanese Wild boars for polymorphisms detection [4-7]. Pig samples for exploration of polymorphisms were collected as ear notches, semen, peripheral blood, or muscle tissues, and genomic DNA was extracted by a standard method. cDNA was synthesized from RNA derived from peripheral blood. Polymorphisms were searched for by direct sequencing of PCR products covering the coding sequences generated with DNA and gene-specific primers. Targeted single nucleotide polymorphisms (SNPs) in additional samples were explored by mass spectrometry with a Sequenom MassARRAY Compact. To investigate the correlation between pneumonia and TLR2 genotype, we fed 626 Landrace pigs on a Mycoplasma hyopneumoniae (Mhp)-positive farm until they weighed 105 to $115 \mathrm{~kg}$. The pigs were then sacrificed and inspected for hepatization of the lung lobes as an indicator of pneumonia. The experiment was conducted in accordance with the animal experiment regulations of Miyagi Livestock Experiment Station.

\section{Results and discussion}

\section{Distribution of polymorphisms in pig PRRs}

We searched for polymorphisms in the coding sequences (CDSs) of TLRs (TLR1, 2, 3, 4, 5, 6, 7, and 8), RIG-I-like helicases (DDX58 encoding RIG-I and IFIH1 encoding MDA5), and a NOD-like receptor (NOD2). We found many polymorphisms in the CDSs, particularly in the regions encoding domains required for ligand recognition [4-7]. Many SNPs changing the encoding of amino acids (nonsynonymous SNPs) were included in the ligand-recognizing regions. Notably, abundant nonsynonymous polymorphisms were observed in the ectodomains of TLRs expressed on cell surfaces (Table 1). In contrast, there were few nonsynonymous SNPs in the regions encoding domains related to signal transduction to the downstream pathways. (Table 1). The occurrence of polymorphisms in the domain in charge of ligand recognition may enable pig populations to cope with a broad variety of pathogens, whereas the occurrence of polymorphisms in the domain required for signal transduction has been strongly suppressed, possibly because of their harmful effects on the innate immunity of the hosts.

\section{Functional influence of polymorphisms in pig PRRs on molecular recognition}

Polymorphisms affecting the encoded amino acids in PRRs may influence molecular function-particularly ligand specificity. However, it is possible that the mutations remaining in the pig population have no effects, and that we can observe only those polymorphisms that are not harmful to molecular function. Therefore, we conducted reporter assays using expression vectors carrying the observed polymorphisms. Human cells (HEK293) into which expression vectors carrying some of the PRR polymorphisms had been introduced showed varying responses to a ligand. For example, the response of pig NOD2 with a $1949 \mathrm{~T} \rightarrow$ C mutation to muramyldipeptide was completely abolished, whereas that of pig NOD2 with $2197 \mathrm{~A} \rightarrow \mathrm{C}$ showed an increased response to the ligand [4]. Furthermore, we have so far detected several nonsynonymous SNPs in TLR2, TLR4, and TLR5 that affected their molecular function in ligand recognition (Shinkai et al., unpublished data).

\section{Possible correlation between PRR polymorphisms and onset of infectious diseases}

The influence of the polymorphisms on ligand recognition ability suggested a relationship between disease susceptibility and PRR genotype. We surveyed the incidence of pneumonia caused mainly by Mycoplasma

Table 1 Distribution of polymorphisms in CDSs of porcine PRRs

\begin{tabular}{|c|c|c|c|c|c|c|c|c|c|}
\hline \multirow[t]{2}{*}{ Gene } & \multicolumn{3}{|c|}{ All } & \multicolumn{3}{|c|}{ Region for ligand recognition } & \multicolumn{3}{|c|}{ Region for signal transduction } \\
\hline & All & NonSyn & Syn & All & NonSyn & Syn & All & NonSyn & Syn \\
\hline$T L R 1$ & 45 & 21 & 24 & 34 & 17 & 17 & 5 & 1 & 4 \\
\hline$T L R 2$ & 23 & 11 & 12 & 17 & 10 & 7 & 3 & 1 & 2 \\
\hline TLR3 & 15 & 6 & 9 & 9 & 3 & 6 & 2 & 0 & 2 \\
\hline TLR4 & 13 & 7 & 6 & 10 & 7 & 3 & 1 & 0 & 1 \\
\hline TLR5 & 35 & 13 & 22 & 21 & 11 & 10 & 12 & 1 & 11 \\
\hline TLR6 & 20 & 11 & 9 & 14 & 10 & 4 & 2 & 0 & 2 \\
\hline$T L R 7$ & 15 & 3 & 12 & 12 & 3 & 9 & 2 & 0 & 2 \\
\hline$T L R 8$ & 22 & 9 & 13 & 20 & 7 & 13 & 0 & 0 & 0 \\
\hline NOD2 & $44^{*}$ & $14^{*}$ & 30 & 17 & 7 & 10 & 6 & 1 & 5 \\
\hline DDX58 (RIG-I) & 17 & 6 & 11 & 8 & 2 & 6 & 3 & 1 & 2 \\
\hline IFIH1 (MDA5) & 3 & 3 & 0 & 1 & 1 & 0 & 0 & 0 & 0 \\
\hline
\end{tabular}

SNPs derived from 11 breeds, including Japanese wild boar (except for NOD2, DDX58, and IFIH1; six breeds of pig were used) were examined for polymorphisms. SNPs observed in the entire CDSs (All), in the ligand recognition region, and in the signal transduction region are indicated. Numbers of polymorphisms of NOD2 include an insertion/deletion polymorphism located in the signal leader sequence (indicated by asterisks). NonSyn, nonsynonymous SNPs; Syn, synonymous SNPs. 
Table 2 Relationship between TLR2 genotype and occurrence of pneumonia

\begin{tabular}{ccc}
\hline Genotype & Cases & Controls \\
\cline { 2 - 3 } & $n$ & $n$ \\
\hline$C / C$ & 331 & 245 \\
$C / G$ & 28 & 9 \\
\hline
\end{tabular}

Pigs of a Landrace population were used to investigate the occurrence of pneumonia caused mainly by Mycoplasma hyopneumoniae. Genotypes were demonstrated by changes in the nucleotide at position 406 in the CDS.

hyopneumoniae in a Landrace population and investigated genotypes of TLR2, which is responsible for recognition of Gram-positive bacteria. Among 626 pigs, 37 had a $G$ nucleotide instead of a $C$ at position 406 in the CDS, causing an amino acid alteration from proline to alanine. Seventy-six percent (28 animals) of pigs with the $\mathrm{G}$ allele showed histopathological signs of pneumonia, whereas 57\% (331 animals) of those without the G allele had pneumonia (Table 2). The former had a significantly greater incidence of pneumonia than the latter (odds ratio $=2.30 ; 95 \%$ interval: $1.07-4.97 ; P=0.038$ ). This suggests a relationship between PRR genotype and disease susceptibility, although we have to examine the susceptibility of animals with the homozygous $G$ alleles to pneumonia. Further investigation with other pig populations may elucidate correlations between other SNPs in PRRs and disease susceptibility.

\section{Conclusions}

Many polymorphisms occur in the genes encoding PRRs in pigs. Some of the polymorphisms have an influence on ligand recognition ability. Polymorphisms in PRRs may be correlated with disease resistance in pigs.

\section{Abbreviations}

PRR: pattern recognition receptors; TLR: Toll-like receptors; CDS: coding sequence.

\section{Acknowledgements}

This work was partly supported by the Animal Genome Project of the Ministry of Agriculture, Forestry, and Fisheries of Japan, and by Grants-in-Aid from the Japan Racing Association.

This article has been published as part of BMC Proceedings Volume 5 Supplement 4, 2011: Proceedings of the International Symposium on Animal Genomics for Animal Health (AGAH 2010). The full contents of the supplement are available online at http://www.biomedcentral.com/1753$6561 / 5$ ? issue $=$ S4.

\section{Author details}

${ }^{1}$ National Institute of Agrobiological Sciences, Tsukuba, Ibaraki 305-8602, Japan. ${ }^{2}$ Institute of Society for Techno-innovation of Agriculture, Forestry and Fisheries, Tsukuba, Ibaraki 305-0854, Japan. ${ }^{3}$ National Institute of Animal Health, Tsukuba, Ibaraki 305-0856, Japan. ${ }^{4}$ United Graduate School of Agricultural Sciences, Kagoshima University, Kagoshima 890-0065, Japan. ${ }^{5}$ Miyagi Livestock Experimental Station, Miyagi Prefecture, Osaki, Miyagi 9896445, Japan.

\section{Authors' contributions}

$\mathrm{HU}, \mathrm{HS}, \mathrm{TM}$, and YM designed the study. HU, HS, TM, K, and CKS detected the polymorphisms. Reporter assays were performed by HS, TM, and KJ. HS, YM, CKS, and ES performed the pneumonia study. HU wrote the manuscript.

\section{Competing interests}

The authors declare that they have no competing interests in this study.

Published: 3 June 2011

\section{References}

1. Akira S, Uematsu S, Takeuchi O: Pathogen recognition and innate immunity. Cell 2006, 124:783-801.

2. Schröder NW, Schumann RR: Single nucleotide polymorphisms of Toll-like receptors and susceptibility to infectious disease. Lancet Infect Dis 2005, 5:156-164.

3. Uenishi $H$, Shinkai $H$ : Porcine Toll-like receptors: the front line of pathogen monitoring and possible implications for disease resistance. Dev Comp Immunol 2009, 33:353-361.

4. Jozaki K, Shinkai H, Tanaka-Matsuda M, Morozumi T, Matsumoto T, Toki D, Okumura N, Eguchi-Ogawa T, Kojima-Shibata C, Kadowaki H, Suzuki E, Wada Y, Uenishi H: Influence of polymorphisms in porcine NOD2 on ligand recognition. Mol Immunol 2009, 47:247-52.

5. Kojima-Shibata C, Shinkai H, Morozumi T, Jozaki K, Toki D, Matsumoto T, Kadowaki H, Suzuki E, Uenishi H: Differences in distribution of single nucleotide polymorphisms among intracellular pattern recognition receptors in pigs. Immunogenetics 2009, 61:153-160.

6. Morozumi T, Uenishi $\mathrm{H}$ : Polymorphism distribution and structural conservation in RNA-sensing Toll-like receptors 3, 7, and 8 in pigs. Biochim Biophys Acta 2009, 1790:267-274.

7. Shinkai H, Tanaka M, Morozumi T, Eguchi-Ogawa T, Okumura N, Muneta Y, Awata T, Uenishi H: Biased distribution of single nucleotide polymorphisms (SNPs) in porcine Toll-like receptor 1 (TLR1), TLR2, TLR4, TLR5, and TLR6 genes. Immunogenetics 2006, 58:324-330.

\section{doi:10.1186/1753-6561-5-S4-S27}

Cite this article as: Uenishi et al.: Polymorphisms in pattern recognition receptors and their relationship to infectious disease susceptibility in pigs. BMC Proceedings 2011 5(Suppl 4):S27.

\section{Submit your next manuscript to BioMed Central and take full advantage of:}

- Convenient online submission

- Thorough peer review

- No space constraints or color figure charges

- Immediate publication on acceptance

- Inclusion in PubMed, CAS, Scopus and Google Scholar

- Research which is freely available for redistribution

Submit your manuscript at www.biomedcentral.com/submit 